\title{
EDUCAÇÃO: UM ESTUDO COM BASE NO RELATÓRIO DA UNESCO SOBRE OS QUATRO PILARES DO CONHECIMENTO
}

\section{ARTIGO ORIGINAL}

RODRIGUES, Zuleide Blanco ${ }^{1}$

RODRIGUES, Zuleide Blanco. Educação: Um estudo com base no relatório da UNESCO sobre os quatro pilares do conhecimento. Revista Científica Multidisciplinar Núcleo do Conhecimento. Ano 06, Ed. 01, Vol. 04, pp. 53-60. Janeiro de 2021. ISSN: 2448-0959, Link de acesso: https://www.nucleodoconhecimento.com.br/educacao/quatro-pilares

\section{RESUMO}

Este trabalho toma como referência a obra "Educação: Um Tesouro a Descobrir" de Jacques Delors, preparada para a UNESCO, sobre os quatro pilares do conhecimento: aprender a conhecer, a fazer, a conviver e a ser, tratando-se de uma pesquisa bibliográfica. $O$ problema que motivou este trabalho está em mostrar que a modificação profunda dos quadros tradicionais da existência humana, coloca-nos perante a novo empenho de compreender melhor o outro ser social e o mundo ao redor. O objetivo geral espera sensibilizar pessoas ligadas ao processo educacional a perceberem que a prática da educação hoje tem como base a visão que a pessoa humana é levada a atendimento de fatores externos, sem o devido instigar da autonomia de raciocínio. Os pilares têm por objetivos específicos: conduzir as pessoas pela educação ao longo da vida a trilhar o caminho do autoconhecimento, para desenvolver a personalidade de forma integral; sedimentar o espírito de equipe, criatividade e o respeito às diferenças; despertar desde cedo a consciência de que uma educação pautada nos quatro pilares do conhecimento formará os líderes do futuro. A conclusão que encerra o trabalho mostra que a atual evolução da sociedade,

${ }^{1}$ Mestre em Educação, História, Política e Sociedade - PUCSP. 
oposto à máquina de produção, está a exigir novas proposituras de absorção do conhecimento, da feitura, da convivência e de ente social nesta Era do Conhecimento.

Palavras-chave: conhecer, fazer, conviver, ser, modificar.

\section{INTRODUÇÃO}

Jacques Delors (2001), em importante trabalho para a UNESCO, indica: "Os quatro pilares da educação para o século XXl”, que traz o mérito de auxiliar as pessoas comprometidas com a prática pedagógica de qualidade. Afirma este autor que ampliar o conhecimento possibilita entender 0 ambiente em que se vive, incentivar a curiosidade, provocando a conquista da autonomia e usar do senso crítico para entender a realidade. Continuando Jacques Delors (2001) diz que à criança é eficaz ter o conhecimento científico por procedimentos adequados, aproximando-a da ciência. O construtivismo, teoria de Jean Piaget sobre a construção do conhecimento, leva em conta que as crianças gostam da ciência pela possibilidade do entender o sentido científico do mundo e agir sobre ele. Splitter e Sharp (1999, p. 63):

Pelo menos em teoria, uma abordagem construtivista é vista como preferível à didática ultrapassada onde o professor e/ou o livro representam "a verdade" sobre a ciência, e onde a tarefa dos alunos e aprender que a verdade, independente de quaisquer crenças e compreensões (ou confusões), eles mesmos podem trazê-la à aula de ciências.

Assim exposto, os autores dizem que o objetivo pedagógico que os professores de ciências perseguem é introduzir essas crenças e compreensões nas aulas, com o objetivo de proporcionar aos alunos o conhecimento científico que lhes permita avaliar o mundo.

Isto posto, os quatro pilares da educação devem orientar a atuação dos educadores a desenvolverem aprendizagens apropriadas às transformações vivenciadas da realidade. Respaldam, também, a formação holística do indivíduo, com habilidades para argumentar, oferecer opiniões fundamentadas, contra argumentar o dito com raciocínio lógico e atingir o juízo final. 
O aprender a conhecer leva a compreensão do mundo que o cerca, abertura para o conhecimento de si mesmo e do outro, que o afasta da ignorância. $O$ aprender a fazer conduz a praticar o conhecimento absorvido, que o afasta do imobilismo. $\mathrm{O}$ aprender a conviver o direciona ao trabalho em equipe, que $\mathrm{o}$ afasta do isolamento. $\mathrm{O}$ aprender a ser que solidifica os pilares e os harmoniza para conformar o ser humano íntegro.

Os quatro pilares são interdependentes e formam um único aprendizado. Que dirige a pessoa humana à construção dos saberes, das aptidões, das capacidades de discernir, do agir e do avaliar de forma ampla e integral.

Jacques Delors (2001), sugere como necessidade a aprendizagem ao longo da vida em um mundo que aspira por conhecimento raciocinado, formador de homens capazes de tomadas de decisão, onde impere a justiça, a ordem e os resultados positivos. Portanto, formar o homem que busque a compreensão da essência dos fenômenos, íntegro e, que permita a todos um mundo melhor para viver. Desta feita, o estudo dos quatro pilares é complemento plausível para quem se compromete com a educação de qualidade.

\section{OS QUATRO PILARES DA EDUCAÇÃO PARA O SÉCULO XXI}

Os quatro pilares da Educação para o século XXI que Jacques Delors (2001) remete a UNESCO, na forma de relatório, compreende o: Aprender a Conhecer, Aprender a Fazer, Aprender a Conviver e Aprender a Ser. Apresentamos a seguir uma breve discussão de cada um desses pilares.

\subsection{O APRENDER A CONHECER (APRENDER A APRENDER)}

Este pilar versa sobre a compreensão do mundo que habitamos e de nós mesmos, do objetivo de se viver dignamente, da necessidade de se desenvolver capacidades apropriadas a realidade atual, voltadas ao raciocínio lógico com autonomia.

Assim, desde tenra idade, é imprescindível se despertar o interesse por novas descobertas, instrumentalizando o conhecimento com paradigmas atualizados. 
O conhecimento evolui de forma rápida e em várias direções, o que torna quase impossível o conhecimento total. O indicado por este pilar do aprender a conhecer é buscar a ampla cultura geral e colocar o foco em determinados assuntos de interesse, aprofundando os detalhes para torna-los ótimos. A cultura geral permite facilitar a comunicação, quando já se tem o conhecimento de outras linguagens. Com o conhecimento aprofundado em outras linguagens, o indivíduo sente a facilidade de comunicação e interação com as outras pessoas e, poderá se manter cooperativo em quaisquer circunstâncias.

O Aprender a aprender compõe-se do todo necessário do aprender a conhecer e requisita a constante atualização em exercitar a memória e o pensamento, além de prestar atenção às coisas e às pessoas. A velocidade com que ocorrem as informações, devido à rápida evolução dos meios tecnológicos, podem prejudicar o encontro com as descobertas, pois estas demandam tempo maior para alcançar o conhecimento recebido. Este tempo é primordial na execução de tarefas diárias como participação em jogos, atualização continuada, viagens, afazeres práticos de ciências e outros.

Os professores, em geral, fazem seus planos de aulas com requintes de conteúdo e técnicas que irão aplicar, mas esquecem de pensar e planejar o que os alunos vão fazer com ou sobre este conteúdo. Como afirma Doug Lemov (1967): Pensar a respeito e planejar as atividades dos alunos é crucial. Ajuda a ver a aula pela perspectiva deles e mantê-los engajados de forma produtiva.

Especialistas em cérebro afirmam que as crianças devem ser preparadas, desde cedo, a exercitarem os vários tipos de memória. O exercício da memória, onde ficam armazenadas as ideias e imagens, deve ser preservado. Isto não se aplica ao exercício da memória associativa, que é a habilidade do cérebro em recordar por associação. Por exemplo: a simples lembrança do cheiro de uma comida, pode nos afastar ou agradar no contato com o mesmo prato, tempos depois. A memória, como função cognitiva, permite tanto as informações ativas, quanto as transitórias (METRING, 2014). Continua esse autor informando que a memória inclui habilidades 
de armazenar, recordar e reconhecer fatos e atividades cognitivas, tais como: compreensão, aprendizado e raciocínio.

O pensamento, parte integrante do aprender a conhecer, deve contemplar situações do concreto ao abstrato, do método indutivo ao dedutivo. No método indutivo, o pensamento caminha da indução para se chegar à conclusão. No método dedutivo, o pensamento caminha da análise geral para a particular, até a conclusão. No exercício do pensar deve-se optar pelo método, que melhor se ajuste ao caso. Ou a usar os dois imbricados.

Aprender a conhecer deve fazer parte do desenvolvimento humano, ao longo de sua existência, e se tornará aprendizado eficaz ao conseguir produzir nas pessoas, o impulso e as bases das suas atividades.

\subsection{O APRENDER A FAZER}

Como ensinar o aprender a fazer a partir do aprender a conhecer que é evolutivo e incerto? Se falamos em evolução o ensinar a fazer adquire variadas conjunturas. Assim, as aprendizagens também são evolutivas embora as de rotina pedagógica continuem a ter o valor formativo, o que não pode ser negligenciado, pois compõe sua competência pessoal.

A competência pessoal faz com que o conhecimento inteligente se coloque em prática, o qual é valorizado no fazer. Não basta fazer, é preciso ser criativo e inovador, fazer por sua inteligência estudada e organizada com que as máquinas se tornem mais inteligentes, facilitando o trabalho e ganhando em produção.

Isto resulta em exigências de educação que vá além do trabalho rotineiro, para a capacitação técnica e profissional, adaptação ao trabalho coletivo em equipe, que exercite a criatividade, a iniciativa, ser ousada e propensa a desafios. Para Kamii (2003), o educador ao interagir com a criança, dá ênfase ao aprender a colocar suas próprias ideias. 
O desenvolvimento no setor de serviços, hoje, não pode ser resistente às mudanças, muito embora o novo, por lidar com o desconhecido, possa desestabilizar o chão do trabalhador. $O$ dirigente empresarial, que assume compromisso pessoal com 0 trabalho e com o trabalhador, pode se tornar um agente transformador, desenvolvendo capacidades de comunicar, de trabalhar em equipe, de gerir e resolver conflitos, importantes habilidades exigidas no comando de uma empresa.

O trabalho assalariado existe desde que se tornou prática, a troca da força de trabalho por salário. Esta fase do trabalho é caracterizada pela relação interpessoal de dependência. Esta foi a chamada Era Industrial. Anteriormente, vivenciamos a Era da Agricultura, pela qual o relacionamento interpessoal era quase nulo, pois se caracterizava pelo individualismo. O desenvolvimento dos serviços, nesta Era do Conhecimento, não se dá nem pela dependência, menos ainda pelo individualismo. A exigência é pelo trabalho coletivo, com a efetiva relação social e eficaz entre as pessoas.

Cada vez mais, a realidade que vivemos está no alcance de formar o profissional social, ligado à cultura científica com acesso à tecnologia atualizada, agregada às capacidades de inovação e criação do contexto local.

\subsection{O APRENDER A CONVIVER, VIVER JUNTOS, APRENDER A VIVER COM OS OUTROS}

Como participar na criação do futuro? Aprendendo a conviver. A viver e a trabalhar junto a outros, apresentar proposições, participar de planos e projetos, comemorar conquistas, na família e no trabalho, esta é a direção do aprendizado fundamental. No educacional o mesmo aprendizado se aplica. Portanto, é imprescindível o aprender a viver com os outros, com respeito à dignidade, diversidade, competências de um e de outro e excluir "Bullying" do convívio social. Trabalhar em projetos de interesse comum, o que implica em nova postura perante a si mesmo, o outro e a realidade.

A descoberta do outro permite nos conhecermos melhor, porquanto envolve atuar no campo das atitudes e valores. A empatia entra nesse jogo, conhecendo a si mesmo é 
possível colocar-se no lugar do outro e aprender que a convivência pacífica pode ser o caminho para a conquista de um futuro melhor. O aprofundamento no ensino da diversidade religiosa, étnica e cultural pode ser fundamental para este aprendizado, pois o conhecimento é instrumento ativo na mudança de paradigmas comportamentais.

Aprender a conviver é o mecanismo da educação para pessoas em desenvolvimento. Essa educação deve tender para objetivos comuns, atenuando diferenças. Quando se trabalha em cooperação nas atividades esportivas, culturais, nas apresentações de feiras de livros, de profissões, a tendência é estabelecer uma convivência de ajuda, de encadeamento de ideias e de alegria. Os conflitos perdem força e abrem espaço para a construção de um grupo coeso, harmonioso e feliz, sendo referência para a vida futura.

\subsection{O APRENDER A SER}

Para Kant, no fim do século XVIII: O homem é a única criatura que precisa ser educada, e continua Charlot (2000), o homem nasce inacabado, precisa fazer-se por si mesmo, é frágil, mas possui plasticidade, não é como o animal irracional definido pela espécie, então vai se definindo ao longo de sua história.

O relatório apresentado para a UNESCO alerta que a educação seja processo contínuo, ao longo da vida, em constante atualização e que vise a qualidade total. Desta forma, o aprender a ser contribui com a formação integral do indivíduo, em todos os setores do conhecimento, quais sejam, inteligência, habilidades para o pensar e com critérios do raciocínio lógico, da argumentação fundamentada na cultura, nas diversidades e no conhecimento científico.

Enfim, o aprendizado ao longo da vida não se resume aos ensinamentos pedagógicos de sala de aula, mas se fundamenta na interação com o outro e com o fazer próprio. Sabemos que a criança aprende muito com seus pares em quaisquer ambientes que estejam, aprendem muito com o que veem e ouvem no mundo. Tanto na sala de aula como fora dela, as crianças adquirem capacidade para discutir e explorar assuntos 
relevantes, num contexto de confiança e respeito mútuos. (SPLITTER e SHARP, 1999)

O aprender a ser deve ser valorizado no mundo atual por preparar o indivíduo ao longo da vida para desenvolver 0 aprender a conhecer, o aprender a fazer, o aprender a conviver e o aprender a ser, no sentido literal da palavra SER como pessoa. A aprendizagem deve ser integral, sem negligenciar nenhuma potencialidade de cada indivíduo.

\section{CONSIDERAÇÕES FINAIS}

Este trabalho sobre os quatro pilares do conhecimento para a educação de qualidade do século XXI, com ênfase no relatório de Jacques Delors, nos coloca ao encontro do grande desafio por uma educação holística, atuante nas áreas da medicina, da psicologia, da ecologia, da formação pedagógica para mudar nossa história e conseguir novas conquistas. Que sejamos capazes de alcançar uma sociedade mais justa e solidária e, acima de tudo, acreditar no poder transformador da educação.

\section{REFERÊNCIAS}

CHARLOT, Bernard. Da relação com o saber: elementos para uma teoria. Tradução de Bruno Magne. - Porto Alegre : Artmed, 2000.

DELORS, Jacques e outros. Educação: um tesouro a descobrir - 5 eds. - São Paulo: Cortez: Brasília, DF: MEC: UNESCO, 2001.

DOUG, Lemov. Dados Internacionais de Catalogação na Publicação (CIP), (Câmara Brasileira do Livro, SP. Brasil - Aula nota 10: 49 técnicas para ser um professor campeão de audiência: Tradução de Leda Beck; consultoria e revisão técnica Guiomar Namo de Mello e Paula Louzano - São Paulo: Da Boa Prosa, 2011.

KAMII, Constance. A Teoria de Piaget e a Educação Pré-Escolar - Tradução de José Morgado - 3 ed. Instituto Piaget - Lisboa - 2003. 
METRING, Roberte Araújo. Neuropsicologia e aprendizagem: fundamentos necessários para planejamento de ensino. 2 eds. - Rio de Janeiro: Wak Editora, 2014.

PIAGET, jean. O Nascimento da Inteligência na Criança - Tradução de Álvaro Cabral, 4 eds. LTC Editora - Livros Técnicos e Científicos Editora S. A. 1966

SPLITTER, Laurence J. e SHARP, Ann M. Uma Nova Educação: A Comunidade de Investigação na Sala de Aula - Tradução Laura Pinto Rebessi - Editora Nova Alexandria Ltda. 1999.

Enviado: Dezembro, 2020.

Aprovado: Janeiro, 2021. 